\title{
Can The Use of Environmental and Sustainability Films Influence Undergraduates' Environmental Worldviews?
}

\author{
Michael W. Everett ${ }^{1}$, Crystal L. Eustice ${ }^{2}$, and Matt R. Raven ${ }^{3}$ \\ ${ }^{1}$ Professor of Practice, Michigan State University, East Lansing, MI, U.S.A. \\ ${ }^{2}$ Assistant Professor of Practice, Michigan State University, East Lansing, MI, U.S.A. \\ ${ }^{3}$ Professor, Michigan State University, East Lansing, MI, U.S.A.
}

\begin{abstract}
.
In a world where climate change is an increasingly important topic, changing behavior though unique educational approaches may stimulate change in students' environmental worldview. Use of film is one instructional approach that provides this unique perspective for undergraduate student learners. Integration of film in courses has the potential to increase environmental attitudes through the operationalization of narrative transportation by students transporting themselves into the narrative of the film or another literary work. The purpose of this research was to determine if relationships existed between narrative transportation and environmental attitudes by film theme in an undergraduate environmental and sustainability film course. Overall, new ecological paradigm (NEP) subscales indicated an increase between pre- and post-course survey results indicating that environmental and sustainability films did influence environmental attitude. Results also indicated that there were moderate correlational relationships between student narrative transportation scores and several NEP subscale items for climate, energy, and environmental and sustainability films. These results suggest that certain NEP subscales are influenced by student narrative transportation into film theme storylines. Therefore, based on the NEP scale and subscales analyses, environmental worldview is influenced by the use of environmental and sustainability films as a teaching approach. The authors recommend further research to better understand how different environmental and sustainability themed films relate to narrative transportation of students.
\end{abstract}

Keywords: environmental attitude, narrative transportation, NEP 


\section{2nd World Conference on Teaching and Education}

19-21 February, 2021 Vienna, AUSTRIA

\section{Introduction.}

Use of environmental and sustainability films as an instructional approach provides a unique way to implement change in a students' ecological worldview. Levey suggests that one way to improve the educational experience is through integration of film into undergraduate learning (2015). Interest in learning and enthusiasm toward teaching using film as a mechanism to stimulate learning is one way to increase cognitive growth in students (Filene, 2005). This occurs when curriculum is reinforced through the use of another form of narrative (e.g., film or popular writing). The use of narrative transportation theory is one way to better understand how film or the written word can be used to induce empathy, mental imagery and detachment from the real world while creating an environment conducive to learning (Green and Brock, 2000). Use of film as a tool for learning college curricula has occurred across a wide range of disciplines including business (Levey, 2015), psychology (Mannes and Ingaglio, 2015), engineering (Joshi, 2012), geography (Smiley, 2017), criminal justice (Cozine, 2015), medicine (Ventura and Onsman, 2009), and agriculture (Scott and Weeks, 2015). Use of one- to two-minute film clips to reference subject matter (Ventura and Onsman, 2009) and incorporation of complete full-length movies or TV features are the range of examples used to teach course content in college settings (Levey, 2015). Additionally, Galbraith and Rodriguez (2018) suggest that unique teaching approaches have the potential to enhance discussion and learning. Agyris (1980) does cite that use of narrative case studies may be counter to the learning process, however counter arguments to these teaching approaches are limited.

This study draws from previous theory and empirical literature on narrative transportation and NEP to explore undergraduates in a College of Agriculture and Natural Resources (CANR) environmental and sustainability film course. This study utilizes undergraduate film students' self-reported narrative transportation perceived values during individual class sessions in an effort to better understand students' worldview toward ecological systems over time. Although the focus of this study is undergraduate students in an environmental and sustainability film course, previous research suggests learning has the potential to change one's ecological worldviews over time (Raven et al., 2018). Limited research exists regarding socio-psychological factors that may provide support for understanding student learning as it relates to film-based curriculum and the NEP scale. Previous socio-psychological research by Everett and Raven $(2015,2016,2018)$ suggest that flow theory or optimal experience may have the potential to quantify these dynamic approaches in an educational setting as suggested by the National Research Council (2009). Previous research using the Experience Sampling Method (ESM) as an event-contingent approach to determine engagement of students through the experiential process supported unique learning in an undergraduate classroom (Everett \& Raven, 2015, 2016, 2018). In cited studies, optimal learning experiences for undergraduates occurred, however use of film as a teaching approach was not used as a teaching and learning technique in conjunction with student NEP scores. 


\section{2nd World Conference on Teaching and Education}

19-21 February, 2021 Vienna, AUSTRIA

\subsection{New Ecological Paradigm}

According to Dunlap (2008), the New Ecological Paradigm (NEP) is a valid and reliable scale used to measure environmental attitudes (EA). Environmental attitudes (EA) are defined as the degree that humans and the environment interact from an "ecological" perspective (Dunlap, 2008). Historically, an environmental paradigm shift began to emerge out of the constructs of the Dominant Social Paradigm (DSP) when Dunlap and Van Liere (1978) posited that there was a need for a paradigm shift that would measure human relationships and their value to the environment. Dunlap and Vanliere (1978) recognized that there were three central concepts around which the paradigms were in opposition to the DSP including: (a) limits to human growth, (b) balance between human and nature, and (c) antianthropocentrism where anthropocentrism is defined as nature and natural resources exist for human consumption and poses no inherent value without human interaction (Dunlap et al., 2000). The NEP has the ability to capture the measurement of anthropocentrism through one's worldview as opposed to specific environmental events. This measure of anthropocentrism makes the NEP unique to other EA scales (Dunlap et al. 2000).

NEP scores range from 15 to 75 with each of the five subscales ranging from 3 to 15 . Lower scores indicate support of the DSP in which one views the human relationship with the environment from an anthropocentric perspective. Scores in the higher range of the spectrum support the New Ecological Paradigm (NEP) in which iterations of that relationship are more focused on the environment and ecosystems. NEP indicators of EA are measured using two sub-scales including ones "ecological worldview," and the "human exemptionalism paradigm." Personal "ecological worldview" is defined as humans are a part of nature and must realize this perspective when utilizing resources. An individuals' "human exemptionalism paradigm" provides human exemptions from the laws of nature and rules over the physical world. Within the NEP scale instrument, "human exemptionalism" items are reversed. Research by Dunlap et al. (2000) suggests that the NEP scale is valid in the determination of environmental behavior. The validity and reliability of the NEP scale has also been supported by Kaltenborn et al. (2012) and Raven et al. (2018) in the context of outdoor recreation and education, respectively. Over time, Dunlap et al. (2000) renamed the New Ecological Paradigm and updated the 15-item scale to maintain the strong reliability and validity of its predecessors in measuring EA (Hawcroft \& Milfont, 2010).

While the NEP has been used worldwide, few studies were found that utilized the NEP with undergraduate students in a college of agriculture and natural resources. One study conducted by Everett and Raven (2019) determined if there were differences in NEP score based on class size in an undergraduate Introduction to Sustainability course using an active learning approach to teaching. The authors found no statistical differences between student NEP scores from three class sections ranging from 39 to 60 students. Although limited 


\section{2nd World Conference on Teaching and Education}

research exists regarding NEP scores of undergraduates (Everett \& Raven, 2019), this study does not a reflect a specific type of teaching approach for each class session (e.g., film), however amplifies a positive shift in a students' ecological worldviews during a semester course.

\subsection{Narrative Transportation}

Undergraduate education utilizing the pedagogical approach of storytelling can be a powerful medium for learning (Dreon et al., 2011). Individual learner being absorbed in the teaching message or storyline through the narration process has the potential to effect real-world-beliefs through transportation into the narrative world (Green and Brock, 2000). Gerrig's (1993) description of transportation theory indicates that an individual or "traveler" is transported as a function of performing certain actions (e.g., watching a film or reading a book). During these travels, the individual moves some distance from their point of origin to locations that may seem inaccessible. Nell (1988) suggests that this inaccessibility refers to an individual's ability to lose access to real world facts in favor of the narrative world (e.g., written, audio or visual). When returning from "travels," the individual indicates being changed by the journey, hence transportation into the narrative and increasing one's cognition of information.

Research by Green et al. (2008) indicated that those who watch films are more likely to be transported in relation to those who read the book version. Additionally, individual differences in cognition increased effectiveness of an individuals' ability to transport in books versus films. The authors indicate that narrative persuasion of movies may provide a more appropriate venue for cognition as compared to similar written versions of the film (Green et al., 2008). Levey (2015) supports this work as it relates to engagement and interest at the undergraduate level of learning through the use of film to support content. Green et al. (2008) also indicates that transportation through the use of movies supports understanding of content and compares the experiences to flow and the relationships associated with challenge and skill of an activity as indicated by Csikszentmihalyi, M. and I.S. Csikszentmihalyi (1988). Green et al. (2008) also suggest that for maximum cognition of subject matter, reading appropriate content followed by watching movies enhanced the transport mechanism. The authors also indicate that matching the movie narrative to appropriate reading material is critical to cognition and engagement (Green et al., 2008). Research by Ventura and Onsman (2009) support Green and colleagues' approach of complimenting classroom instruction with appropriate narrative transportation as important to classroom learning and engagement in content. 


\section{2nd World Conference on Teaching and Education}

19-21 February, 2021

Vienna, AUSTRIA

2. Purpose/Objectives

The purpose of this study was to determine the associations between students' ecological worldviews and their narrative transportation theory experiences in a film course with a sustainability theme. This study was guided by the following research questions:

1) Were there differences in students' ecological world view as measured by the NEP in a community sustainability film course that utilizes narrative transportation theory?

2) What is the relationship between students' NEP subscale scores and narrative transportation by film theme in the context of a course using film to explore environmental and sustainability issues?

\section{Methods}

Data were collected at Michigan State University in the fall semester of 2018 in a sophomore-level course offered in the Department of Community Sustainability. The course is a selective for Environmental Studies and Sustainability (ESS) students. There were 60 undergraduates enrolled in the course and all students participated in the study. The narrative transportation survey was a modified version from Green and Brock (2000). The NEP scale was a modified version originally developed from Dunlap (2008). The Michigan State University Institutional Review Board deemed this study exempt.

This study used event-contingent sampling (i.e., taking a paper-pencil survey during specific activities over the course of the semester class). Participants were provided with instructions at the first course session by the researcher prior to taking the first narrative transportation survey. At the first course session, participants were provided with a consent form and narrative transportation survey and asked to fill out this and successive surveys based on the viewed film and their experiences in relation to the movie. Students developed a self-selected code that would provide individual anonymity during future narrative transportation surveys. Additionally, during the first course session, students were also asked to fill out the 15-item New Ecological Paradigm (NEP) instrument based on their current attitudes and worldview about the environment. At the end of the semester students were then asked to re-take the NEP instrument to determine changes in their ecological worldview over the course of the semester.

For this study, 60 participants completed a total of 713 narrative transportation surveys, which amounts to a response rate of $84.8 \%$ (14 measured activities x 60 students $=840$ total potential responses). In an effort to obtain consistent and reliable narrative transportation data, incomplete surveys were not included in the data set for analysis. By comparison, Everett and Raven had a response rates of $76 \%$ for an event-contingent sample of pre-service undergraduate agriculture, food, and natural resources education students (2015) and $83 \%$ for a study of College of Agriculture and Natural Resources undergraduate 


\section{2nd World Conference on Teaching and Education}

leadership course students (2018). Thus, the response rate of the present study was deemed acceptable for this study. The narrative transportation instrument was determined to be reliable through previously conducted research (Green \& Brock, 2000). Additionally, internal consistency of the scale for this study was measured using Chronbach's alpha for narrative transportation (.92) and NEP (.90), which supports prior internal consistency reliability claims.

Films from the course were categorized by theme. The four themes and associated movies included: (1) climate systems (The Island President, The Day After Tomorrow, Carbon Nation, and Downsizing), (2) food systems (Food, Inc., More Than Honey, The True Cost, and Sustainable), (3) energy systems (Gasland Part II, The Last Mountain, and Garbage Warrior), and (4) general environmental and sustainability movies (Erin Brockovich, The Cove, and Expedition Happiness). Two faculty experts from the Department of Community Sustainability reviewed categories to ensure that movies were categorized within appropriate thematic areas.

The variables for this analysis fall into three categories. The first category references demographics questions related to age, gender and major of students. The second category of variables measured aspects related to narrative transportation (summed score). Narrative transportation summated scores ranged from 12 to 60. The third category of variables includes both NEP pre- and post-course student surveys. Each of the subscales consisted of three items from the NEP survey. The summed NEP scale determines an individual's environmental attitude. A 5-point Likert scale interval was also used with a scale ranging from strongly disagree (1) to strongly agree (5).

Data were analyzed using the SPSS 24.0 statistical software package. Descriptive statistics were calculated to determine measures of central tendency for demographic and assessment of variables. Correlations were reported as follows: 1) a strong correlation for Pearson (r) values between \pm 0.50 and $\pm 1.00 ; 2)$ a moderate correlation for $(r)$ values between \pm 0.30 and \pm 0.50; and 3) a weak correlation for ( $r$ ) values between 0 and \pm 0.30 (Cohen, 1992). Pearson's Correlational Coefficient was used to test relationships between demographic information collected (age and gender), narrative transportation constructs, and NEP summated items. Narrative transportation was calculated by the summation of scale items. Total NEP was calculated by summating all instrument items with scores ranging from 1575. The results of this study are not being generalized beyond the scope of this research study.

\section{Findings/Results}

Student respondents in the CSUS265 course $(n=60)$ were representative of seven U.S. States and five different countries. Females represented over 66 percent of respondents with an average age of all students being $20 \pm 3.3$. Twenty-seven majors in seven Colleges 


\section{2nd World Conference on Teaching and Education}

were represented in the course at Michigan State University in the fall of 2018. Fifty percent of respondents had primary majors in one of the three Department of Community Sustainability's Bachelor of Science (B.S.) degree programs (Agriculture, Food and Natural Resources Education, Environmental Studies and Sustainability, and Sustainable Parks Recreation and Tourism). Additionally, sixty-seven percent of students were majors in the College of Agriculture and Natural Resources. New Ecological Paradigm (NEP) scale results indicated that pre-NEP student means were $56.9 \pm 9.1$ and post-NEP mean scores were $58.5 \pm 13.0$ (Table 1$)$.

Reality of limits to growth is defined as "limiting to growth beyond which our industrial society cannot expand" (Dunlap, 2008, p. 7). Mean pre-NEP reality of limits to growth was $10.4 \pm 2.6$, whereas post-NEP was $11.0 \pm 2.4$ (Table 1). Therefore, over the semester course, students increased their opinion that we are limited in the ability of growth and expansion on the planet. Antianthropocentrism is defined as the rejection of "the belief that nature exists primarily for human use and has no inherent value of its own" (Dunlap et al., 2000 , p. 431). Mean subscale pre-NEP scores ranged from $11.5 \pm 2.6$ to post-NEP of 12.2 \pm 2.5 (Table 1) indicating that student's belief that nature does not exist primarily for human use and consumption increased. Fragility of nature's balance is defined as that which "humans must live in harmony with nature in order to survive" (Dunlap, 2008, p. 7). Fragility of nature's balance mean subscale pre-NEP scores ranged from $11.1 \pm 2.2$ to postNEP mean score of $12.2 \pm 1.9$ (Table 1) indicating that students increased in their belief that humans and nature are equally valuable over the entirety of the course. Rejection of exemptionalism is defined as the rejection of the idea that "humans, unlike other species, are exempt from the constraints of nature" (Dunlap et al., 2000, p. 432). Mean subscale pre-NEP scores ranged from $10.5 \pm 2.4$ to post-NEP mean score of $11.2 \pm 2.1$ (Table 1). Despite student beliefs that humans are subject to nature, many students did not believe that human ingenuity can help solve these challenges, therefore suggesting that course films (e.g., The Day After Tomorrow) may have influenced beliefs about climate change. According to Dunlap et al., possibility of eco-crisis is defined as the "likelihood of potentially catastrophic environmental changes or 'eco-crises' besetting humankind" (2000, p. 432). Possibility of eco-crisis mean subscale pre-NEP scores ranged from $13.4 \pm$ 2.0 to a post-NEP mean score of $14.0 \pm 1.3$ for all students (Table 1 ). Therefore, indicating that over the duration of the course, environmental and sustainability films increased students' beliefs that an eco-crisis may beset humankind in the future. 


\section{2nd World Conference on Teaching and Education}

19-21 February, 2021

Vienna, AUSTRIA

Table 1: Descriptive statistics of pre- and post-NEP course scores and NEP subscales from a sophomorelevel film course $(n=60)$

\begin{tabular}{lcccc}
\hline NEP Subscale & $\begin{array}{c}\text { Pre-NEP } \\
\text { Mean } \pm \text { SD }\end{array}$ & $\begin{array}{c}\text { Pre-NEP } \\
\text { Min (Max) }\end{array}$ & $\begin{array}{c}\text { Post-NEP } \\
\text { Mean } \pm \text { SD }\end{array}$ & $\begin{array}{c}\text { Post-NEP } \\
\text { Min } \\
(\text { Max })\end{array}$ \\
\hline Reality of Limits of Growth & $10.4 \pm 2.6$ & $3(15)$ & $11.0 \pm 2.4$ & $4(15)$ \\
Antianthropocentrism & $11.5 \pm 2.6$ & $3(15)$ & $12.2 \pm 2.5$ & $5(15)$ \\
Fragility of Nature's Balance & $11.1 \pm 2.2$ & $3(15)$ & $12.2 \pm 1.9$ & $8(15)$ \\
Rejection of Exemptionalism & $10.5 \pm 2.4$ & $3(15)$ & $11.2 \pm 2.1$ & $6(14)$ \\
Possibility of Eco-crisis & $13.4 \pm 2.0$ & $3(15)$ & $14.0 \pm 1.3$ & $9(15)$ \\
Total NEP & $56.9 \pm 9.1$ & $15(71)$ & $58.5 \pm 13.0$ & $15(71)$
\end{tabular}

Note: Data is from Exploring Environmental and Sustainability Issues and Policy Using Film a sophomore-level course with 60 students taught in the 2018 fall semester at Michigan State University.

Narrative transportation results indicated relationships with most NEP subscales (Table 2). Climate themed movies indicated low to moderate relationships with the subscales of antianthropocentrism (0.28), fragility of nature's balance (0.35), and possibility for ecocrisis (0.36). Food themed movies had a moderate correlation with the possibility for ecocrisis (0.32, Table 3$)$. Whereas, energy themed movies had low correlations with the reality of limits of growth (0.29) and possibility of eco-crisis (0.27), and a high correlation with fragility of nature' balance (0.51). Finally, moderate Pearson (r) relationships existed within environment and sustainability themed movies and fragility of nature's balance (0.41) and possibility of eco-crisis (0.36). Collectively, positive relationships across many film themes indicate that students were transported into the narrative for many of the NEP subscale items within all themes of movies (Table 2). Specifically, film themes influenced transportation by students and the potential for ecosystem changes or a catastrophe that may influence individual environmental attitudes. This is supported by moderate relationships within the climate, energy and environmental themed movies and the subscale that there is fragility of nature's balance.

Table 2: Pearson ( $r$ ) correlations between movies themes by new ecological paradigm (NEP) subscales scores and narrative transportation $(n=60)$

\begin{tabular}{l|c}
\hline $\begin{array}{l}\text { Movie Themes } \\
\text { NEP Subscale }\end{array}$ & $\begin{array}{c}\text { Narrative } \\
\text { Transportation }\end{array}$ \\
\hline Climate & \\
Reality of Limits of Growth & .06 \\
Antianthropocentrism & $.28^{*}$ \\
Fragility of Nature's Balance & $.35^{* *}$ \\
Rejection of Exemptionalism & .10
\end{tabular}




\section{2nd World Conference on Teaching and Education}

\section{9-21 February, $2021 \quad$ Vienna, AUSTRIA}

\begin{tabular}{l|l}
\hline Possibility of Eco-Crisis & $.36^{* *}$ \\
Food & \\
Reality of Limits of Growth & .15 \\
Antianthropocentrism & .21 \\
Fragility of Nature's Balance & .11 \\
Rejection of Exemptionalism & -.06 \\
Possibility of Eco-Crisis & $.32^{*}$ \\
& \\
Energy & $.29 *$ \\
Reality of Limits of Growth & .19 \\
Antianthropocentrism & $.51^{* *}$ \\
Fragility of Nature's Balance & .08 \\
Rejection of Exemptionalism & $.27 *$ \\
Possibility of Eco-Crisis & \\
& .07 \\
Environment and Sustainability & .20 \\
Reality of Limits of Growth & $.41^{* *}$ \\
Antianthropocentrism & .01 \\
Fragility of Nature's Balance & $.36^{* *}$ \\
Rejection of Exemptionalism & $.39 * *$ \\
Possibility of Eco-Crisis & \\
Total NEP Score & \\
&
\end{tabular}

${ }^{*} p<.05 .{ }^{*} p<. \overline{01}$. Note: Data is from Exploring Environmental and Sustainability Issues and Policy Using Film a sophomore-level course with 60 students taught in the 2018 fall semester at Michigan State University.

\section{Conclusion/Implications/Recommendations}

As climate change continues to be a topic of discussion worldwide (Dessler \& Parson, 2020), it is important that individuals understand and promote their ecological worldview as a way to stimulate future dialogue about the Earth as an ever-changing ecosystem. This study sought to utilize an undergraduate course to increase student EA using the NEP with film as an experiential learning approach used to stimulate a student's ecological worldview. The course was designed to immerse students in environmental and sustainability content through the narrative of learning (e.g., narrative transportation).

Comparisons of NEP scores by undergraduate film students indicated moderately strong overall pre- and post-NEP scores that were consistent with previous research by Everett and Raven (2019) in a similar class size setting. Additionally, subscale increases were also consistent with overall NEP results. Descriptive results of items suggest that students have strong environmental attitudes that increased during the undergraduate film course. This result indicates that using film as a teaching approach in an undergraduate environmental and sustainability course holds promise in changing the paradigm of an undergraduates' ecological worldview. At a time when the YouTube movement is at an all-time high with 


\section{2nd World Conference on Teaching and Education}

Millennial and Gen $\mathrm{Z}$ populations, educating the world about environmental and sustainability awareness using film is an approach that is supported through the data in this study. As an increase in NEP scores appears to be affected by film and film theme, the author suggests further research comparing different types of instruction with film being one pedagogical approach.

Consistent relationships between narrative transportation and NEP score were not found. Possibility for eco-crisis relationships were moderate in all cases with respect to narrative transportation scores. Therefore, students were more likely to be transported into the narrative during films that were also likely to increase and promote a process for understanding an eco-crisis worldview. Additionally, a fragility of nature's balance theme was also found to have moderate correlations with students being narratively transported into climate, energy and general environmental and sustainability themed movies. In both instances, understanding types of movies that are more likely to transport students into the film narrative provides valuable information to instructors with a goal of broadening students' ecological worldviews about environmental and sustainability course content.

Overall, this research provides support that students who are narratively transported into certain themed movies may also increase their ecological worldview through specific subscales of the NEP. This context for learning indicated that a course using film media may be an important teaching approach for current undergraduates while providing a new perspective for learning in a college of agriculture and natural resources setting (National Research Council, 2009). Future research should include replication of themed film experiences as a way to determine validity of the narrative transportation and NEP instrumentation and potential for application in other environmental and sustainability courses. Research should also include measurement of cognition of subject matter when written material is used in conjunction with film as indicated by Green et al. (2008). Additionally, the authors encourage additional research that focuses on categories of films (e.g., documentaries and fictional dramas) rather than film themes (e.g., food, climate) as a way to better understand how narrative transportation influences student learning. Limitations of this study included the sample size $(n=60)$, limited scope and sequence of potential movies presented during the course, and potential for recall bias as related to students filling out narrative transportation surveys at the conclusion of each class session. This study supports similar narrative transportation research conducted by Green and Brock (2000) as it is important to learning and provides the impetus for further studies using socio-psychological indicators to develop teaching approaches that motivate and engage undergraduate university students in the $21^{\text {st }}$ century and beyond. 


\section{2nd World Conference on Teaching and Education}

19-21 February, 2021

Vienna, AUSTRIA

\section{References}

Cohen, J. (1992). A power primer. Psychological Bulletin, 112(1), 155-159.

Cozine, K. (2015). Setauket to Abbottabad: The value of film and television in teaching human intelligence. Journal of Strategic Security, 8(2), 80-92.

http://doi.org/10.5038/1944-0472.8.3.1467

Csikszentmihalyi, M. and Csikszentmihalyi, I. S. (1988). Introduction to Part IV. In M. Csikszentmihalyi and I. S. Csikszentmihalyi (eds.), Optimal experience:

Psychological studies of flow in consciousness (pp. 251-265). Cambridge, UK:

Cambridge University Press.

Dessler, A. E. and Parson, E. A. (2020). The science and politics of global climate change: A guide to the debate ( $3^{\text {rd }}$ edition). Cambridge, UK: Cambridge University Press.

Dunlap, R. E. (2008). The new environmental paradigm scale: From marginality to worldwide use. The Journal of Environmental Education, 40(1), 3-18.

Dunlap, R. E., Van Liere, K. D., Mertig, A. G. and Jones, R. E. (2000). Measuring endorsement of the new ecological paradigm: A revised NEP scale. Journal of Social Issues, 56(3), 425-442.

Dunlap, R. E. and Van Liere, K. D. (1978). The "New environmental paradigm." The Journal of Environmental Education, 9(4), 10-19.

Dreon, O., Kerper, R. M., and Landis, J. (2011). Digital storytelling: A tool for teaching and learning in the YouTube generation. Middle School Journal, 42(5), 4-10.

https://doi.org/10.1080/00940771.2011.11461777

Everett, M. W. and Raven, M. R. (2019). Effective Class Size for Active Learning in an Undergraduate Introduction to Sustainability Classroom. Journal of the North American Colleges \& Teachers of Agriculture, 63(1), 93-99.

Everett, M. W. and Raven, M. R. (2018). Measuring Optimal Experiences of CANR Undergraduates in a Leadership Course. Journal of Agricultural Education, 59(1), 35-50. http://doi.org/10.5032/jae.2018.01035

Everett, M. W. and Raven, M. R. (2016). Relationships between "flow" and undergraduate experiences in a college of agriculture leadership course. Journal of the North American Colleges \& Teachers of Agriculture, 60(2), 213-218. 


\section{2nd World Conference on Teaching and Education}

Everett, M. W. and M. R. Raven. (2015). A case study of flow theory in pre-service undergraduate agriculture, food and natural resources education students. Journal of the North American Colleges \& Teachers of Agriculture, 59(2), 144-148.

Filene, P. (2005). The joy of teaching: A practical guide for new college instructors, 7. Chapel Hill, NC: The University of North Carolina Press.

Galbraith, C. and Rodriguez, C. (2018). Student engagement and enjoyment of narratives: An empirical study of an authentic music video and a short teaching case. College Teaching, 66(4), 171-180.

Gerrig, R. J. (1993). Experiencing narrative worlds. New Haven, CT: Yale University Press.

Green, M. C., Kass, S., Carrey, J., Herzig, B., Feeney, R. and Sabini, J. (2008). Transportation across media: Repeated exposure to print and film. Media Psychology, 11(4), 512-539. http://doi.org/10.1080/15213260802492000

Green, M. C. and Brock, T. C. (2000). The role of transportation in the persuasiveness of public narratives. Journal of Personality and Social Psychology, 79(5), 701-721.

Hawcroft, L. J. and Milfont, T. L. (2010). The use (and abuse) of the new environmental paradigm scale over the last 30 years: A meta-analysis. Journal of Environmental Psychology, 30(2), 143-158.

Joshi, A. (2012). Multimedia: A technique in teaching process in classrooms. Current World Environment, 7(1), 33-36.

Kaltenborn, B. P., Andersen, O., Vitterso, J. and Bjerke, T. K. (2012). Attitudes of Norwegian ptarmigan hunters towards hunting goals and harvest regulations: the effects of environmental orientation. Biodiversity \& Conservation, 21(13), 3369-3384. http://doi.org/10.1007/s10531-012-0368-1

Levey, B. R. (2015). Using film clips in the classroom: Something old, something new? Journal of Teaching and Learning with Technology, 4(2), 41-50. http://doi.org/10.14434/jotlt.v4n2.13140

Mannes, S. and Ingaglio, Jr., R. (2015). A film is worth a thousand words: The impact of film, need for cognition, and experiential thinking on attitudes towards the death penalty. North American Journal of Psychology, 17(2), 351-372. 


\section{2nd World Conference on Teaching and Education}

Nell, V. (1988). Lost in a book: The psychology of reading for pleasure. New Haven, CT: Yale University Press.

National Research Council. (2009). Transforming agricultural education for a changing world. Washington, DC: The National Academies Press.

Raven, M. R., Wittman, M., Everett, M. W. and Rountree, J. E. (2018). Michigan schoolbased agriculture educators' attitudes, beliefs and knowledge of sustainable agriculture. Journal of Agriculture and Environmental Sciences. 6(2), 1-12.

http://doi.org/10.1560/jaes.v6n2a2

Scott, M. and Weeks, P. P. (2015). Using film to teach authentic leadership. Journal of Leadership Education, 15(1), 140-149. http://doi.org/10.12806/V15/I1/A5

Smiley, S. L. (2017). Teaching cultural geography with the amazing race. Journal of Geography, 117(3), 109-118. http://doi.org/10.1080/00221341.2016.1253763

Ventura, S. and Onsman, A. (2009). The use of popular movies during lectures to aid the teaching and learning of undergraduate pharmacology. Medical Teacher, 31(7), 662-664. http://doi.org/10.1080/01421590802641489 